\title{
Criminalidade - prevenção começa pela educação*
}

\author{
Prof. Dr. Daniel Ricardo de Castro Cerqueira**
}

No rastro de 2016, o ano de 2017 nem bem começou e os brasileiros se depararam com o retrato nu e cru da situação de caos dos presídios de Norte a Sul do País. Excesso de população, confrontos violentos entre facções, rebeliões e mortes deram a exata medida de como o Estado perdeu a guerra no combate ao crime, dentro e fora das penitenciárias.

O Brasil é um dos países mais violentos do planeta, respondendo por cerca de $10 \%$ do total de homicídios no mundo. A violência não dá sinais de arrefecimento e, à medida que avança, cresce o número dos que defendem um endurecimento das leis e o encarceramento em massa. “À mercê de uma retórica de que 'bandido bom é bandido morto', estamos lotando as prisões e jogando mais lenha nessa fogueira", alerta Dr. Daniel Ricardo de Castro Cerqueira, da Diretoria de Estudos e Políticas do Estado, das Instituições e da Democracia (DIEST) do Instituto de Pesquisa Econômica Aplicada (IPEA).

Convidado para fazer uma radiografia da violência e sua relação com a educação oferecida aos nossos jovens, especialmente os de maior vulnerabilidade socioeconômica, Dr. Cerqueira aponta o sucateamento das organizações policiais e a inoperância das políticas públicas, e é enfático ao destacar a necessidade de substituir as políticas reativas e truculentas por programas preventivos, especialmente os orientados para a primeira infância. Estudioso das políticas de segurança pública, ele engrossa o coro dos que associam criminalidade à falta de oportunidades e de acesso dos mais pobres aos meios materiais e simbólicos que caracterizam nossa sociedade de consumo.

Dr. Cerqueira, cuja tese de doutorado em Economia pela PUC-Rio (Causas e consequências do crime no Brasil) foi agraciada com os dois principais prêmios de Economia do País (o Haralambos Simeonidis, da Associação Nacional de Pós-Graduação em Economia -

\footnotetext{
* Entrevista concedida à jornalista Joana Gonçalves e publicada na revista SuperVarejo, da Associação Paulista de Supermercados, em julho de 2017.

** Dr. Daniel Ricardo de Castro Cerqueira, doutor em Economia pela PUCRJ, integra a Diretoria de Estudos e Políticas do Estado, das Instituições e da Democracia (DIEST) do Instituto de Pesquisa Econômica Aplicada (IPEA).
} 
Anpec, e o BNDES de Economia), acredita que interromper o ciclo de hiper violência não é tarefa impossível. "Não existem cidades violentas; existem cidades com bairros muito violentos. Basta um trabalho de inteligência capaz de identificar esses locais e comprometimento para desenvolver políticas preventivas focadas e pontuais.”

Por fim, cita o papel do empresário no esforço de combate ao crime, principalmente no sentido de pressionar o poder público e de oferecer oportunidades de emprego e de ressocialização ao indivíduo que passou por programas socioeducativos e mesmo aos egressos do sistema prisional. "Não lhe fechem as portas. Muitas vezes, tudo o que ele precisa é de uma oportunidade!" Com vocês, Dr. Daniel Cerqueira:

\section{Como o IPEA trabalha a questão da violência no Brasil?}

Desde o ano 2000, temos uma agenda de estudos sobre violência e segurança pública, um trabalho que tem como objetivo checar as políticas efetivas de segurança pública no País e ver o que pode ser feito para reverter essa trajetória de tragédia das últimas décadas. São várias subagendas, dentre elas entender as condições socioeconômicas e os elementos sociais que poderiam ser objeto de intervenção pública sob a forma de políticas preventivas. Constatamos que é urgente mudar totalmente o enfoque dessas políticas e o modo como são feitas.

\section{O que temos e o que precisa mudar?}

Temos hoje simplesmente políticas reativas, como botar polícia nas ruas sem saber muito bem para quê, prender criminosos, etc. Não adianta ficar prendendo, prendendo, porque o ciclo de produção de criminosos continua. Para encerrá-lo, além da repressão qualificada e polícia inteligente, são urgentes políticas preventivas, sobretudo para os jovens de comunidades socioeconomicamente mais vulneráveis. Nosso trabalho parte de uma compreensão de que políticas públicas efetivas dependem de um pilar básico que se chama prevenção social, e prevenção social em localidades conflagradas pelo crime, para podermos mudar a trajetória de crianças e jovens nesse perfil. Daí é que surge a agenda educação.

\section{É possível explicar o que nos levou a esse cenário de hiper criminalidade}

A resposta fez parte de minha tese de doutorado em Economia, Causas e consequências do crime no Brasil. Começamos esse estopim de aumento acelerado nas taxas de homicídio no início dos anos 80. A partir dos dados da evolução na taxa de homicídios desde aquele ano, tentamos responder se esse aumento dos homicídios pode ser explicado pelo conhecimento 
acumulado na economia ou não. E produzimos vários indicadores que explicam o porquê dessa realidade hoje. São vários fatores, cuja importância muda de década pra década.

\section{Que fatores nos anos 80 se assemelham aos de hoje?}

A década de 80 ficou conhecida como década perdida. No início daquele período, o Brasil dá o default da dívida e perde espaço nos mercados internacionais. O PIB per capita despenca, a renda do brasileiro cai, há grande concentração de renda e a estagnação econômica perpassa a década, tudo isso em um momento histórico de grande concentração e transformações urbanas. De 1970 a 1980, tivemos o êxodo rural - a população nas metrópoles aumentou quase $50 \%$. As pessoas chegavam do Nordeste, de várias partes do interior, com sonhos de trabalhar, de ter uma boa posição econômica, e encontravam um País em crise. Com falta de emprego e economia estagnada, aumentaram os incentivos a favor do crime.

\section{De certa forma, o retrato do Brasil de hoje.}

Estamos repetindo o que tínhamos lá atrás, obviamente com alguns aspectos menos benéficos e outros mais; alguns positivos, outros negativos. De ruim, tínhamos instituições fracas e hiper inflação, o que não temos agora. O bom é que o país emergia de um período de ditadura militar, havia a expectativa de democratização. Hoje não se tem a inflação de antes, as instituições mal ou bem foram se organizando, mas, depois de mais de trinta anos de democracia, temos a economia desorganizada e um sentimento enorme de desesperança, elementos que já influenciam as taxas de crime.

\section{É possível fazer um paralelo em termos de políticas públicas de combate ao crime daquele momento e agora?}

Se pegarmos o número de homicídios e o percentual de esclarecimento na época, é nítida a total falência do sistema de segurança pública, ditada inclusive pelo aumento da impunidade. $\mathrm{O}$ sistema de segurança pública não estava preparado para entender a complexidade urbana, especialmente em um momento de êxodo e economia em crise. De lá para cá, a sociedade, aturdida com tanta violência, namorou a sereia do populismo penal, do 'vamos nos armar para nos defender'. À mercê de uma retórica de que 'bandido bom é bandido morto', estamos lotando as prisões e jogando mais lenha na fogueira. De quebra, assistimos ao sucateamento das organizações policiais e falta de políticas públicas de segurança racionais e inteligentes. 


\section{Quais os números da violência no Brasil?}

De 1980 para cá o número de homicídios aumentou 385\%, ao passo que o número de encarceramento subiu quase $1.200 \%$. Estima-se que apenas $8 \%$ do número de homicídios são esclarecidos. Na Inglaterra, o índice é 90\%; nos Estados Unidos, 60/70\%. Quando veio a público o caos do serviço prisional no Norte e Nordeste, o ministro da Justiça foi à mídia dizer: 'temos um plano'. Não, não temos. O que temos são ações descoordenadas com o único objetivo de dar uma resposta à sociedade, sem que essa resposta seja necessariamente verdadeira. A única política de segurança pública constante ao longo dessas décadas é aquela feita com base na reação midiática. Acontece um crime ali na esquina, por algum tempo vamos ver viaturas, policiais por perto, etc.

\section{A prisão de grandes atores do mercado e do meio político não é prova de mudanças importantes?}

Com certeza, mas quando vamos para um patamar mais baixo nas relações sociais, encontramos dois elementos aparentemente contraditórios: o forte sentimento de 'vamos prender', 'precisamos de leis mais duras', etc. e tal, e o encarceramento de pessoas que poderiam ter sido punidas com outras penas que não o aprisionamento. Os dados mostram que os que estão presos são os que não deveriam estar - é o pequeno traficante, o cara que furtou o celular, etc. Enquanto isso, vários crimes são cometidos por um grupo pequeno, por homicidas contumazes, que estão soltos pelas ruas.

\section{Existe alguma relação entre criminalidade e baixa escolaridade?}

Não tenho a menor dúvida. Fizemos vários trabalhos sobre o tema, mas não é preciso consultar estatísticas para comprovar isso. Basta entrar em qualquer estabelecimento de execução prisional e constatar que o nível de escolaridade da maioria dos que lá estão é fundamental incompleto. Os encarcerados de norte a sul, de leste a oeste são exatamente aqueles que vieram de uma condição vulnerável do ponto de vista socioeconômico, que não tiveram como participar dos meios de produção, daquele ideal de sucesso determinado pela sociedade de consumo. Muitas vezes, é esse indivíduo sem boa educação que será arregimentado pelo crime organizado e desorganizado lá na frente. E não necessariamente vai ser preso por um crime de alta expressividade, mas passará a fazer parte dessa engrenagem perigosa quando acabar na cadeia por um crime menor. 


\section{Por que isso ocorre?}

Primeiro pela seletividade do sistema penal, que pune esses indesejáveis. A parte mais nobre da sociedade precisa ser protegida, e a forma de protegê-la é pegando os indesejáveis e segregando-os em penitenciárias. Este é um ponto. O outro é uma trajetória a favor do crime que começa no nascimento e segue até a juventude. Educação de qualidade neste País é restrita a um pequeno grupo populacional. A maioria é largada à própria sorte na educação. Educação

significa oportunidade. Se não oferecermos educação de qualidade e mecanismos para que os meninos pobres possam gozar de determinados valores simbólicos da sociedade, nenhuma política pública vai funcionar. Eles querem aparecer, se sentir realizados. Tem de se trabalhar nessas comunidades pobres várias expressões, na arte na cultura, etc., desenvolver instrumentos e mecanismos para que se sintam motivados e parte dessa sociedade.

\section{Então, é correto afirmar a desigualdade social como elemento-chave na produção da violência?}

Com certeza. Quando falo de educação, não me refiro apenas à formal, mas àquela educação que começa antes, na família. Pesquisas identificam problemas comportamentais já desde a primeira infância, de zero a seis anos. Crianças com temperamento difícil, hiperatividade, agressividade, isolamento, etc. têm maiores chances de cometer transgressões e crimes no futuro. Segundo estudos, os problemas surgem por ' $n$ ' razões. Têm a ver, claro, com características individuais associadas a temperamento, índole, etc., mas têm a ver sobretudo com modelos de comportamentos antissociais dos pais dentro de casa e no ambiente externo na primeira infância.

\section{Quais fatores familiares e sociais desencadeiam esses comportamentos?}

O garoto pobre, sob forte estresse e privação econômica, sem uma supervisão competente de adultos, é potencial candidato a apresentar esses problemas. O que vive em favela, muitas vezes em local dominado pelo crime, e em ambiente domiciliar violento vai aprender desde cedo a reagir, a ter a violência como mecanismo de comunicação e pode apresentar transtornos de estresse pós-traumático. Uma vez na escola, esse garoto, que já não se sente como cidadão, que já apanhou em casa, na rua, levou tapa na cara de policiais, é submetido a mais uma violência, que é decorar uma série de coisas que não dizem respeito à vida dele. Vai apresentar hiperatividade, agressividade, vai se isolar, irá mal nos estudos, e será caçoado pelos colegas 
porque é burro. Será excluído, vai se juntar a outros colegas com o mesmo problema e vai aprontar.

Você não acha que é delegado à escola um papel que vai além da responsabilidade dela? Nem sempre os professores estão preparados para receber essa criança desajustada.

O maior cliente do Estado é justamente essa criança que chega à escola já com toda sorte de problemas comportamentais e sócio-emocionais. Em princípio, o papel da escola é ensinar matérias acadêmicas, mas existe ali uma grande massa de garotos que cresceram nessas circunstâncias e desenvolveram problemas cognitivos e emocionais. É preciso reconhecer essas limitações e como elas impedem o aprendizado. O professor passa o dever de casa e diz 'vai e te vira'. Como vai estudar numa casa de um cômodo e sem de se concentrar. E a escola vai repudiá-lo, reprová-lo. Mais adiante, apartado do mundo, da sociabilidade, sem condições de estudar direito, sem emprego e muitas vezes abandonado pela família, esse menino vai ser um aviãozinho, um delinquente. Quando for preso, se fecharão de uma vez por todas as portas para

um possível caminho longe do crime. É a sociedade que lhe diz: 'Vai, prossiga no sentido da criminalidade, pois você não tem outra opção’.

\section{Em que sentido a escola precisa mudar para contribuir com a redução da delinquência juvenil?}

Precisa mudar o formato, o estilo, as atividades e matérias, ao invés de enfiar um monte de conhecimento enciclopédico no aluno. A mente da criança não é um repositório de conhecimento, e se ela não decorou ou foi mal na prova, não pode simplesmente ser posta de lado. Ela precisa ensinar disciplinas básicas, mas também buscar mecanismos capazes de lidar com essas diferenças sociais e psicoemocionais, mirar o conhecimento acadêmico, e perceber quem é aquele jovem e como mudar sua realidade de forma a evitar uma trajetória rumo à delinquência.

Por parte do Estado, cabe desenvolver programas diretamente nas comunidades, com orientações por enfermeiras, assistentes sociais, etc., que visitam as famílias e acompanham essa criança. Nos Estados Unidos, um dos programas de melhor relação custo/benefício é o de orientação desde o nascimento. A cada seis meses, enfermeiras visitam os bairros mais pobres, dão orientações às mães, às grávidas. Estudos comprovam que cada dólar investido nesse programa tem alto retorno para a sociedade, afinal essas crianças começam a trilhar uma trajetória diferenciada daquelas que não participam dele. 


\section{Pode citar um exemplo local de política preventiva com crianças em comunidades violentas?}

Dois programas se destacam: Pacto pela vida, de Eduardo Campos, em Pernambuco; e Estado Presente, de Renato Casagrande, no Espírito Santo. Em ambos, mapearam, identificaram as pessoas, as maiores carências, e que políticas preventivas poderiam levar as crianças, algumas com problemas comportamentais, a uma trajetória longe do crime. Identificaram onde ocorriam os crimes e, ao invés de polícia truculenta nas ruas, utilizaram informação inteligente para uma repressão qualificada e retirada de armas e dos homicidas habituais das ruas. Em ambos a taxa de crimes caiu rapidamente. O Espírito Santo era o segundo entre os cinco Estados mais violentos do País; há sete anos, a taxa de homicídios vem caindo sistematicamente, graças a investimentos nesses pontos detectados.

\section{Por que afirma que não é tão difícil combater o crime?}

Porque criminalidade não é algo que envolve toda a sociedade. São poucos os indivíduos que cometem crimes. Basta um trabalho de inteligência capaz de identificar onde ocorrem os crimes e vontade e comprometimento para desenvolver políticas pontuais preventivas para que crianças e jovens desses locais não se tornem os criminosos de amanhã. Quando era ministro da Justiça, José Eduardo Cardoso anunciou um pacto nacional para redução dos homicídios, e nós, do IPEA, contribuímos com as discussões. Em 2014, traçamos um mapa da violência no Brasil, e observamos que metade dos homicídios acontecia em 71 dos 5.570 municípios. Ao olharmos cada um desses municípios-problema, percebemos que metade dos crimes se dava em $10 \%$ dos bairros, bairros onde o Estado não entrou, onde as pessoas estavam largadas à própria sorte. A exclusão estava lá.

\section{Por que você diz que o Estado é o primeiro a desrespeitar a lei?}

Tudo o que está na lei de execução penal é fragorosamente descumprido pelo próprio Estado. Em levantamento recente pegamos os dados de estabelecimentos penais levantados em inspeções dos promotores do Ministério Público, e constatamos que é ele, o Estado, que arregimenta os indivíduos que vão servir aos grupos de criminosos organizados e desorganizados. Separação de presos tem impacto direto sobre a escola do crime, mas em $80 \%$ dos estabelecimentos não há separação alguma. É uma esculhambação. Criminoso ou não, todo indivíduo tem direitos jurídicos que precisam ser respeitados. Pela legislação, um preso pode 
ficar em regime provisório por no máximo três meses. Hoje mais de $40 \%$ da população prisional são de presos provisórios. Há preso que sequer passou por um juiz, e ninguém é responsabilizado por isso. Às vezes, é o garoto pobre que não teve como se defender, foi ouvido pelo delegado e está lá mofando. É assim que as facções nascem e se desenvolvem. O drama que estamos vivendo nasce do rastro dessa desorganização e desrespeito flagrante por parte do próprio Estado.

\section{Que chances teríamos de imediato no combate à criminalidade?}

No curto prazo, vamos ter ainda um crescimento da criminalidade violenta, não apenas pela questão social. Se, por um lado, a recessão vai impactar os incentivos a favor do crime, por outro, cria incentivos para mudarmos esse cenário. Explico: na década de 2000, como a renda aumentou em muitas cidades Brasil afora, vários mercados ilícitos inviáveis economicamente passaram a ser viáveis, sobretudo o mercado de drogas. E teve início a disputa pela distribuição, gerando mais crimes, violência. Isso persiste, o ciclo não acabou. Pelo menos até 2023, há espaço para crescer, sobretudo, homicídios. A partir de 2023, a expectativa é de uma queda no índice de crimes, por uma questão demográfica. Hoje o Brasil registra a maior quantidade de jovens da história, algo como 53 milhões, e a partir de 2023 esse número deve cair barbaramente. Quem sofre crime é jovem e essa diminuição será elemento a favor da redução da criminalidade.

\section{Ser um agente de transformação implica em quê para o empresário?}

O papel do empresário se dá não apenas no plano da cidadania, mas do autointeresse. Precisa entender a. Se a grande massa de mão de obra que ele recebe já chega com esses vícios, esses problemas comportamentais e baixo aprendizado, isso vai impactar diretamente na lucratividade do negócio. Entendendo a importância da educação desde o nascimento, o primeiro passo é pressão política. Ele tem poder para isso. Um segundo elemento é empregar jovens não apenas em trabalhos maçantes e mal remunerados, mas em tarefas que os estimulem e com salário digno. Terceiro, apostar na ressocialização de egressos dos sistemas penal e socioeducativo. Um jovem que foi preso, por mais que queira iniciar uma trajetória longe da subversão, sofre estigma. Quando houver um crime, o primeiro lugar onde a polícia vai bater é na casa dele, o suspeito padrão. Dificilmente vai conseguir emprego. É mais uma vez a sociedade dizendo: 'prossiga no mundo do crime'. Por isso, não lhe fechem as portas. Muitas vezes, tudo o que ele precisa é de uma oportunidade! 